NASA Technical Memorandum 102014

IAF-88-355

\title{
Facilities for Microgravity Combustion Research
}

Kurt R. Sacksteder

Lewis Research Center

Cleveland, Ohio

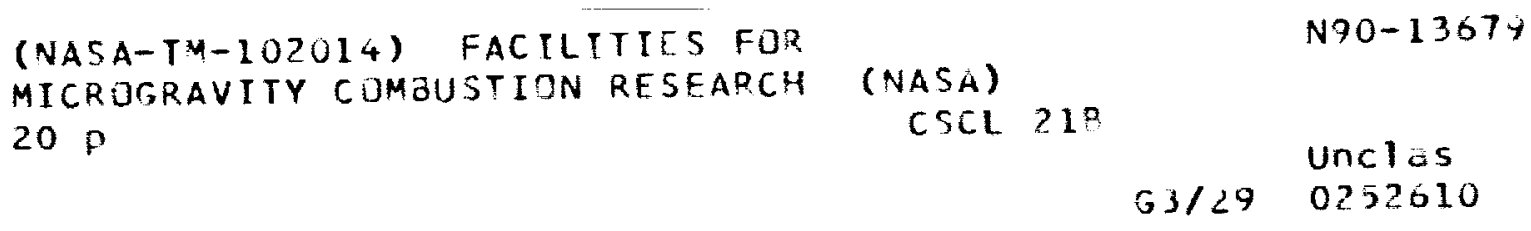

$$
\begin{array}{ll} 
& \text { Unclas } \\
63 / 29 & 0252610
\end{array}
$$

Presented at the 39th Annual Astronautical Congress of the International Astronautical Federation

Bangalore, India, October 8-15, 1988 
$=\ldots+\cdots=\ldots$ 


\title{
FACILITIES FOR MICROGRAVITY COMBUSTION RESEARCH
}

Kurt R. Sacksteder

\author{
National Aeronautics and Space Administration \\ Lewis Research Center \\ Cleveland, Ohio 44135 U.S.A.
}

\begin{abstract}
Combustion science and applications have benefited in unforeseen ways from experimental research performed in the low-gravity environment. The capability to control for the first time the influence of gravitational buoyancy has provided some insight into soot formation in droplet combustion, the nature of flammability limits in premixed gases, and the relationship between normal-gravity and low-gravity material flammability that may influence how materials are best selected for routine use in habitable spacecraft. The opportunity to learn about these complex phenomena is derived from the control of the ambient body-force field and, perhaps as importantly. the simplified boundary conditions that can be established in well designed low-gravity combustion experiments. A description of the test facilities and typical experimental apparatus are provided; and conceptual plans for a Space Station Freedom capability, the modular combustion facility, are described.

\section{INTROOUCTION}

Combustion research in the low-gravity environment originated from the need to test simple theories about the potential hazard of fire in habitable spacecraft. Once the first experiments were performed it became apparent that this unique environment could be used for fundamental studies of combustion phenomena for the benefit of pure science as well as fire safety and other applications (Ref. 1). As the field has developed it has become apparent that there are four principal reasons that reduced-gravity combustion experiments can be useful.
\end{abstract}


Buoyancy-induced convection is a dominant mechanism in many practical combustion systems under normal-gravitational conditions. The ability to choose the ambient level of gravitational acceleration allows the gross influence of buoyancy to be examined. This aspect of low-gravity research is limited because buoyant convection is coupled closely to every other fluid mechanism, and its removal does not leave these other mechanisms unaltered.

Several fluid and thermal mechanisms have been identified that are often overwhelmed by buoyant convection but that can be isolated in low-gravity experiments for detailed study. Surface-tension driven flows, low-speed (subbuoyant) forced flows, flows driven by the expansion of phase changes, heat loss mechanisms near flammability limits, and droplet microexplosions are examples.

of particular relevance to spacecraft fire safety issues, low-gravity combustion experiments allow study of the limiting mechanisms in that environment. Quantification of the relative importance of chemical reaction rates, fuel evaporation or pyrolysis rates, and conduction and convection in the nonbuoyant case are important to the development of fast acting fire detection systems and effective, but low mass and volume, fire extinguishment systems (Refs. 2,3 and 4 ).

Finally, properly conceived low-gravity combustion experiments provide unique experimental boundary conditions including spherical symmetries in droplet/particle and premixed gas systems, and uniform particle distributions in the absence of gravitational settling. Several experimental configurations provide reductions in dimensionality from three dimensions to two or sometimes one dimension.

\section{REDUCED-GRAVITY TEST FACILITIES}

A varlety of facilities are available for performing low-gravity combustion experiments. Ground-based facilities include drop towers and 
specially modified aircraft. The principal attributes of these facilities are the duration of the reduced-gravity test time and the level of acceleration that can be achieved.

Figure 1 shows a sketch of the larger of two drop towers located at the NASA Lewis Research Center. Experiment packages are integrated into a $1 \mathrm{~m}$ diameter bus that are dropped through a $10^{-2}$ torr vacuum for $150 \mathrm{~m}$. Residual accelerations are measured to be below $10^{-6} \mathrm{~g}$ for the drop duration of $5.2 \mathrm{sec}$. In this facility experiments must be hardened against the vacuum and the 30 to $50 \mathrm{~g}$ landing deceleration. A second drop tower at the same location provides $2.2 \mathrm{sec}$ of micro-g level accelerations, but in a drop package falling within a drag shield through air. Thus drop towers provide very short duration but very clean environments of low gravity.

The short experiment time available in drop towers can be used to advantage even for testing phenomena that have longer characteristic times than the drop provides. Because access to these facilities is frequent, multistep phenomena can be decomposed and each step separately exercised. Examples of this technique will be described below in the discussion of specific experiments.

Figure 2 shows an aircraft that has been structurally strengthened to perform maneuvers that provide periods of reduced gravity. The parabolic trajectory is sketched showing approximately 22 to $25 \mathrm{sec}$ of reduced gravity in between periods of 2 to $2.5 \mathrm{~g}$. Typlcal parabolas provide measured acceleration levels of under $10^{-2} \mathrm{~g}$ for 8 to $10 \mathrm{sec}$ and less than $0.1 \mathrm{~g}$ for the remainder. Thus aircraft experiments trade low acceleration levels for extended experiment time and the possibility of experimenter interaction; and avoid the heavy mechanical loading experienced at the end of a drop-tower test.

Larger aircraft have sufficient cabin volume to allow selected experiment packages to free-float. Although significant variation can be expected, 5 to 
$10 \mathrm{sec}$ of test time below $10^{-3} \mathrm{~g}$ are normal between collisions of the experiment package and the cabin wall. In addition to the reduced averaje level of acceleration, free-floated experiments are also somewhat isolated from the normal alrcraft vibrations experienced by attached experiments. Thus as mechanically sensitive diagnostic tools are developed for use in low-gravity combustion experiments, free-floating in aircraft, even with degraded acceleration levels, may provide the best environment for ground-based experiments.

Orbiting low-gravity facilities such as the Shuttle/Spacelab and the space stations Mir and Freedom practically eliminate the limitations on experiment duration and provide acceleration levels between $10^{-3}$ and $10^{-6} \mathrm{~g}$ depending upon crew and machinery activity. The orders of magnitude increase in the cost of experimental hardware for space flight over drop tower or aircraft apparatus demands that flight payload development be undertaken only when the capabilities of ground-based facilities are clearly exhausted.

Two combustion programs including payloads that are being prepared for shuttle flights are described below. Design considerations for the flight hardware were affected by substantial drop tower testing programs and illustrate the importance of thorough precursor tests.

\section{LOW-GRAVITY COMBUSTION TEST APPARATUS}

\section{Solid Surface Combustion}

The spreading of flames over solid fuels is of interest both as a classic problem in combustion science and the central process in the spreading of fires. Flame spread is a complex interaction of chemical processes, including the flame and the decomposition of the solid fuel; and several potential modes of thermal transport. Flame spreading is often classified as opposed flow, with the bulk gas-phase motion moving opposite the flame spread direction; and inversely, concurrent flow. In the context of normal gravity, downward flame 
spread over vertical fuel surfaces is an example of the opposed flow case, where upward moving buoyant flow opposes the downward flame spread. The characteristic velocity of the buoyant flow is determined largely by the flame temperature and thus exhibits a minimum at the limit of flammability.

Low-gravity experiments in flame spreading provide the opportunity to control the buoyant gas-phase motion. Greatly reduced buoyant flow permits the observance of small momentum flows assoclated with the gassification and expansion of the condensed fuel. Experiments can also be configured to create forced flows at velocities below those normally encountered in the normal gravity environment. In experiments with slow opposed flows it has been demonstrated that material flammability limits can be found at lower oxygen concentrations than required to sustain flames in normal gravity. The implications of these experiments in the context of ventilation systems in habitable spacecraft remain to be determined (Ref. 5).

Long duration tests in the absence of forced or buoyant flows are required to examine the flow induced by the gassification of the fuel. The solid surface combustion experiment (SSCE) Shuttle payload is configured to obtain this data. Figure 3 shows the flight hardware for the SSCE. Two camera views and a set of solid phase and gas phase thermocouples provide the principal data with a level of redundancy. Paper or polymethylmathacrylate samples are burnt in varying atmospheric conditions. Figure 4 shows the sample holder for paper samples and indicates the two-dimensional system obtained by burning the sample end to end. A joule heated hot wire ignitor is augmented by a chemical ignitor that, through careful metering, simulates the gas expansion of an established flame.

Extensive drop tower testing that was undertaken to evaluate flight hardware concepts also produced innovation in the separation of ignition phenomena and sustained combustion. In the study of flame spreading; 
low-power (slow acting) ignition will Induce buoyant flow if activated before a drop test to conserve drop time for flame spreading. The induced momentum persists into the low-gravity time and distorts the experiment. Flame spreading experiments require high power but minimum energy ignition to best utilize short low-gravity test times. Low-gravity ignition experiments, however, can be performed separately; and stretched in time to match the total test time. Thus in the $5.2 \mathrm{sec}$ drop tower, $5 \mathrm{sec}$ ignition tests and $5 \mathrm{sec}$ flame spreading tests can both be accomplished.

Droplet Combustion

Droplet combustion is of tremendous consequence in the use of fossil fuels throughout the world and has been a classical problem in combustion for half a century. While the theories of burning droplets all assume the spherical symmetry that the microscopic droplets in practical combustion systems have, until the advent of reduced-gravity experiments it was impossible to produce analogous experimental results at adequate spatial resolutions.

As with flame spreading phenomena, the burning of droplets is strongly affected by the presence of relative motion between the droplet and the surrounding gas phase. Simulation of the theoretical ideal can be approached in low-gravity tests if the droplet can be deployed into the oxidizing environment with little motion. The droplet combustion experiment (DCE) program has developed the technology to release single, nearly motionless (less than 1.0 droplet diameter per second) droplets with the retraction of symmetric fibers. Figure 5 shows a $2.2 \mathrm{sec}$ drop tower droplet combustion apparatus. High speed film cameras record the burning of droplets within the pressure vessel shown, which can be filled with any variety of atmosphere up to $2.0 \mathrm{kPa}$. Off the shelf electronics control the deployment of $1 \mu \mathrm{m}$ simple hydrocarbon or alcohol fuel droplets. Droplets, ignited with electric sparks, 
burn with spherical symmetry, and, if the residual velocity is adequately low, demonstrate the mechanisms of soot formation on a resolvable scale (Fig. 6) (Ref. 6).

The DCE flight hardware, shown in Fig. 7 is configured to provide ten droplets (per mission) for combustion under up to five different atmospheric environments. These tests will include droplets far too iarge to either form or deploy in the time available in the drop towers. Yet drop tower tests are providing the scientific return implied by Fig. 6 as well as engineering data needed for planning the space experiments. The sequence of droplet formation, deployment, ignition, burning, and extinction exceeds the available ground-based test times except for the smallest droplets. To fully exploit the facility, different experiments are performed in which some sequence increments are performed in normal gravity and the remaining increments during the drop. Again, by splitting the process, each element of a long test can be simulated.

\section{Space Station: Modular Combustion Facility}

In the several years that remain before the laboratory faclilities of the Freedom become available, several programs in microgravity combustion should progress through the ground-based science and flight technology development programs and become new candidates for deployment as space experiments. In the context of the proposed 90-day space station mission increment, enough combustion experimentation is anticipated that the feasibility of a dedicated facility within the laboratory modules is indicated.

Conceptual design studies for a modular combustion facility are in progress and no results have been published to date. However some summary information can be described herein.

The design philosophy of the MCF recognizes the diversity of the potential set of users. In the search for adequate flexibility in 
accommodating widely varying test configurations, the modularity concept was conceived. Under this premise a series of reference combustion experiments are envisioned. For each reference experiment a database of hardware requirements is being developed that includes volume, electrical power, heat dissipation, consummables, waste and venting needs, operations logistics, automation functions, data acquisition, telescience requirements and operational and measurement diagnostic systems requirements. A merged data base of several reference experiments provides a ready indication of commonly required equipment and an envelope of laboratory resources that are used to define the facility.

Figure 8 shows the current schematic concept of the modular combustion facility. In this concept, one or more equipment racks will be dedicated to experiment specific hardware that is easily changed out as experiment modules. The facility resources and common equipment are concentrated within an additional equipment rack that serves as the experiment interface with the laboratory module. By dedicating large volumes to unique experiment hardware, the potential combustion experimenter is constrained in experimental creativity only by the requirement to match the electrical and mechanical interfaces defined at the rack boundary.

Additional levels of modularity are included in the design concept. Fig. 9 shows a concept of the contents of the facility resource rack. The electronics consist of discrete subsystems that serve complex functions of power conversion and control, significant video and transducer data acquisition and processing, and support of a wide variety of anticipated combustion diagnostics. Each of these subsystems are modular in the sense that they will be easily replaced either for a reconfiguration of the resource rack or for upgrades in equipment technology. The fluid handing region of the resource rack will provide easily reconfigurable gas-mixing capability, 
control, and processing of experiment waste products before release to the laboratory waste management system, and the interface with the gas supplies provided by the laboratory module.

Experiment modules are envisioned as modular at multiple levels. While each module will have a fundamental configuration, such as a low-speed wind tunnel for subbuoyant velocity experiments, test section changeout capability will be a key design requirement. Thus moving air past burning droplets or solid fuel samples will be accommodated without imposing one experiment's boundary conditions on another.

As history has demonstrated, extensive testing of design concepts for flight hardware will be required for the development of a productive combustion facility. Before facility hardware designs are confirmed, extensive breadboarding and low-gravity testing will be pursued. While time consuming, this approach to flight hardware development has consistently provided unexpected innovation in hardware design and a steady supply of preliminary scientific return.

\section{SUMMARY}

Taking advantage of the low-gravity environment to explore the fundamental mechanisms of combustion under simplified conditions is a new application of space to science. Cost effective use of the precious resource of orbiting laboratories demands that ground-based capability be fully exploited first, experiments chosen for space be definitive and not exploratory, and that flight hardware be reconfigurable for multiple and varied users.

\section{REFERENCES}

1. Berlad, A.L., et al., "Study of Combustion Experiments in Space," NASA CR-134744, 1974. 
2. Sacksteder, K.R., "Microgravity Combustion Fundamentals," Spacecraft Fire Safety (Proceedings of the Spacecraft Fire Safety Workshop, Cleveland, $\mathrm{OH}$, Aug. 20-21, 1986) NASA CP-2476, 1986, pp. 89-94.

3. Friedman, R, and Sacksteder, K.R., "Science and Technology Issues in Spacecraft Fire Safety," AIAA Paper 87-0467, Jan. 1987.

4. Friedman, R., and Sacksteder, K.R., "Fire Behavior and Risk Analysis in Spacecraft," NASA TM-100944, Dec. 1988.

5. 01 son, S.L., Ferkul, P.V., and T'ien, J.S., "Near-Limit Flame Spread Over a Thin Solid Fuel in Microgravity." presented at the 22nd sympcsium (International) on Combustion, Combustion Institute, N.Y., 1988.

6. Shaw, B.D., Oryer, F.L., Williams, F.A., and Haggard, J.B., Jr., "Sooting and Disruption in Spherically Symmetrical Combustion of Decane Droplets in Air," ACTA Astronautics, vol. 17, no. 11/12, Nov./Dec. 1988, pp. $1195-1202$. 


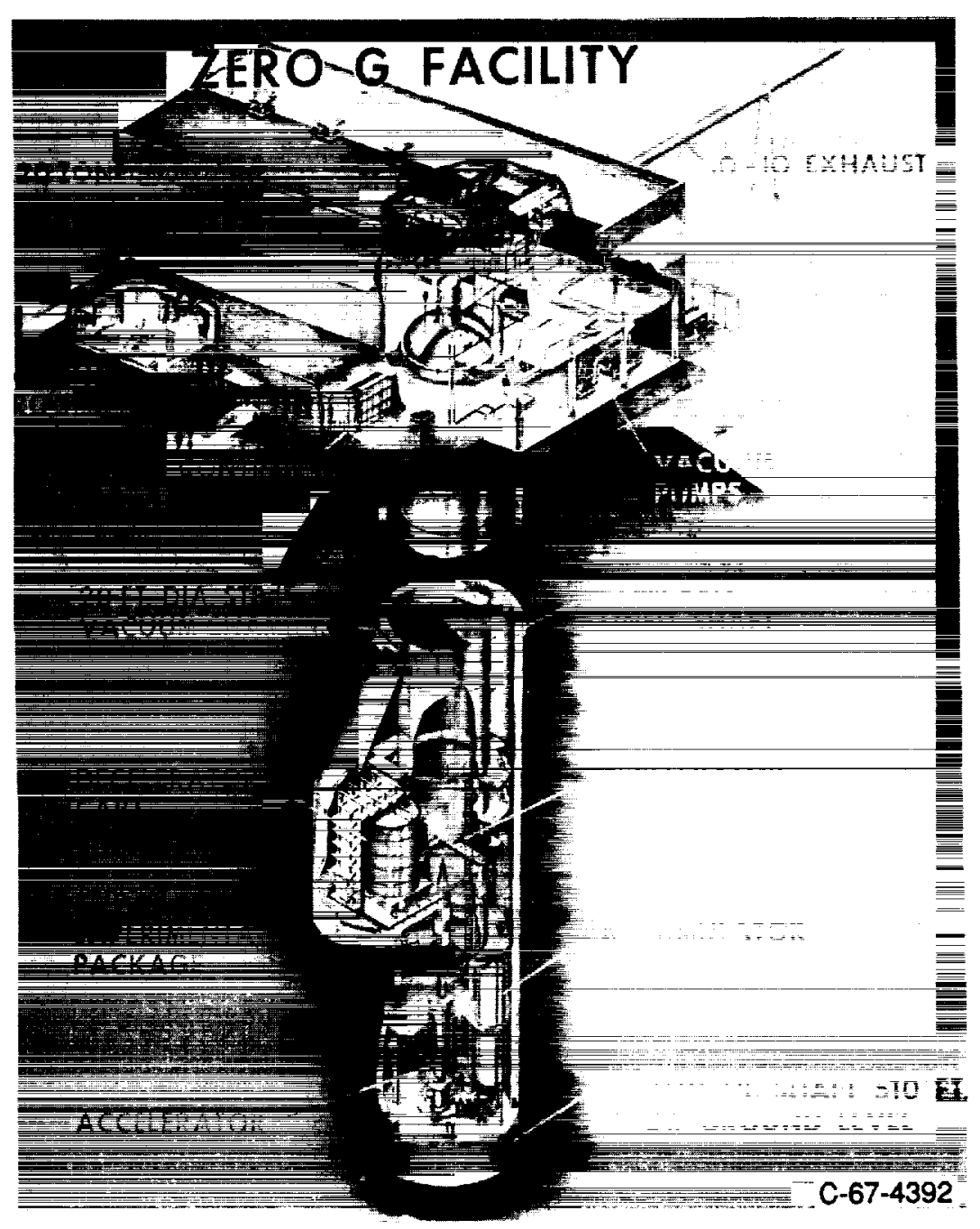

Figure 1. - 5.2 second drop tower.

ORIGINAL PÁĜE

BLACK AND WHITE PHOTOGRAPH 


\section{LERC AIRBORNE REDUCED GRAVITY LABORATORY}

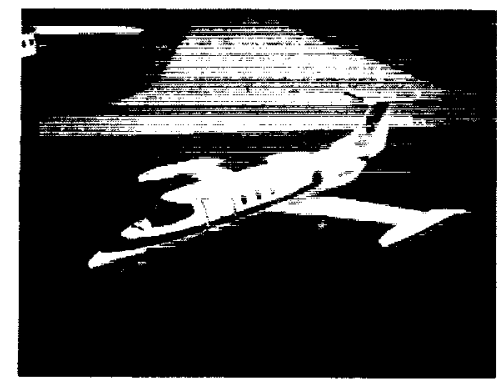

LERC MODEL 25 LEARJET

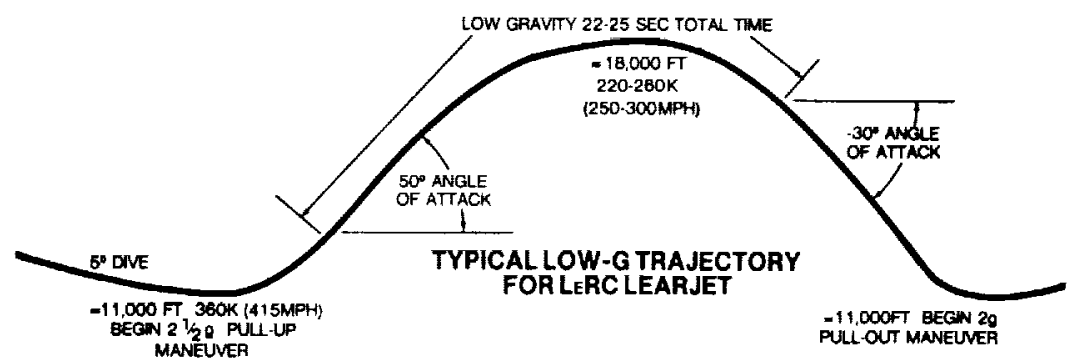

FOR USE IN DEVELOPMENT OF SPACE-EXPERIMENT HARDWARE

- DETERMINE USEABILITY OF HARDWARE COMPONENTS

- SCREENING OF PROPOSED EXPERIMENTAL TECHNIQUES

- PRE-LAUNCH TESTING OF COMPLETE EXPERIMENTS

Figure 2. - Learjet low-gravity facility. 
ORIGINAL PAGE

BLACK AND WHITE PHOTOGRAPH

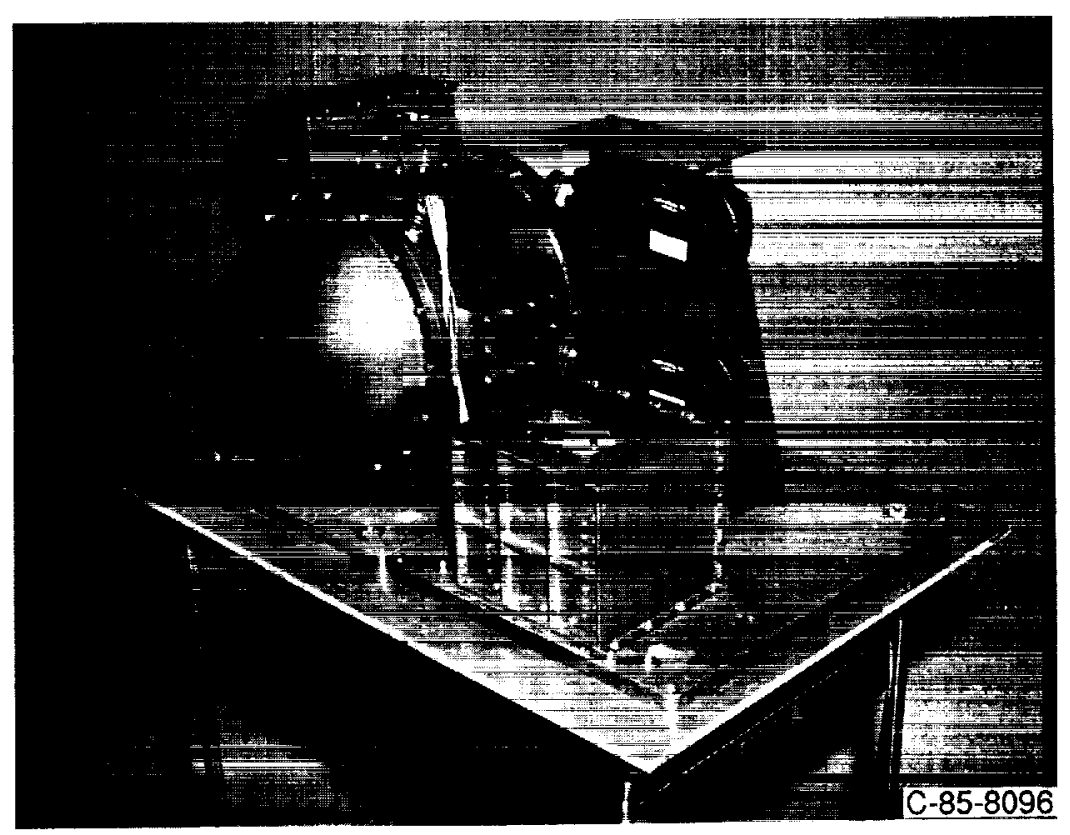

Figure 3. - Solid surface combustion experiment engineering hardware. 


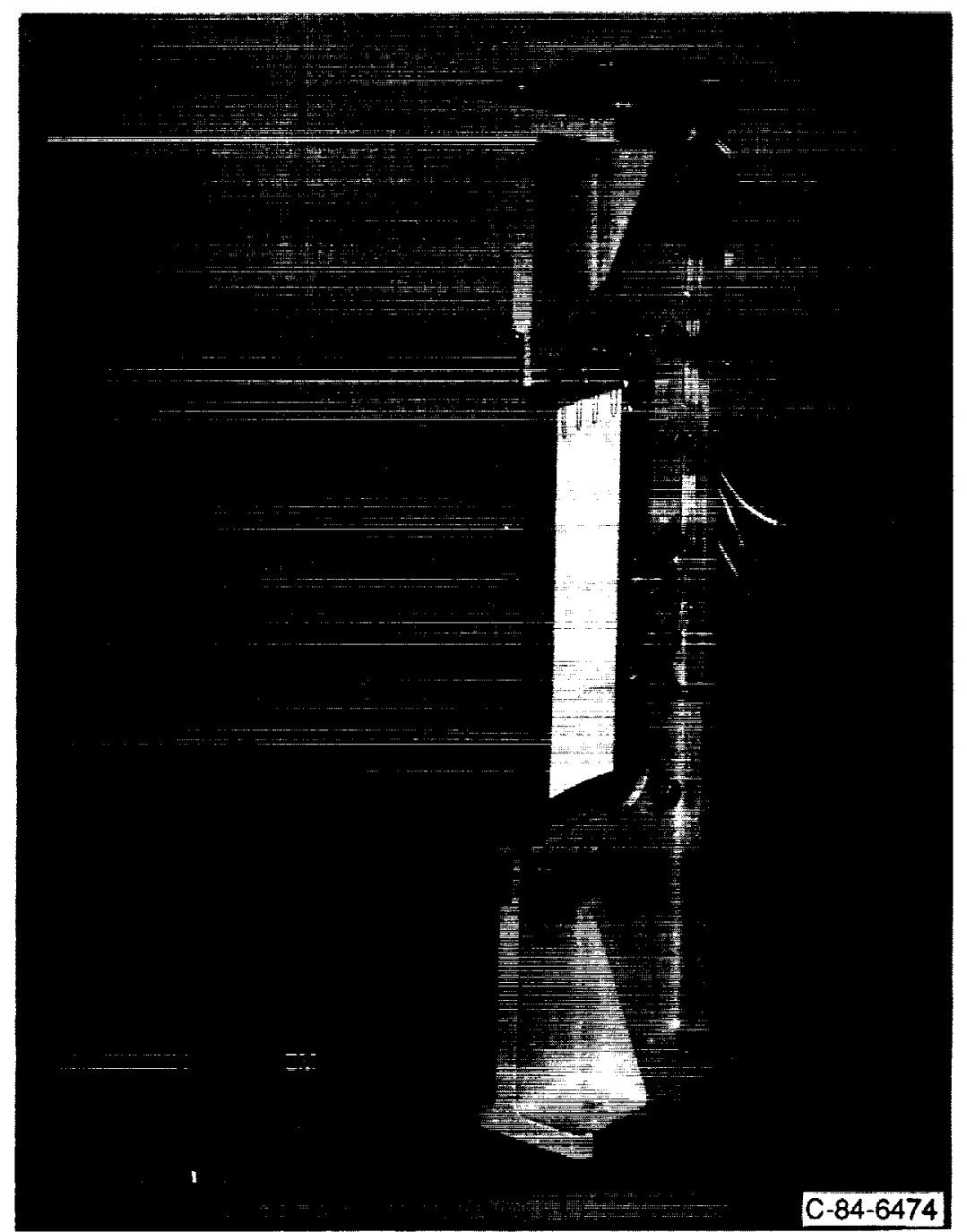

Figure 4. - Paper specimen holder.

\author{
ORIGINAL PAGE \\ BLACK AND WHITE PHOTOGRAPH
}




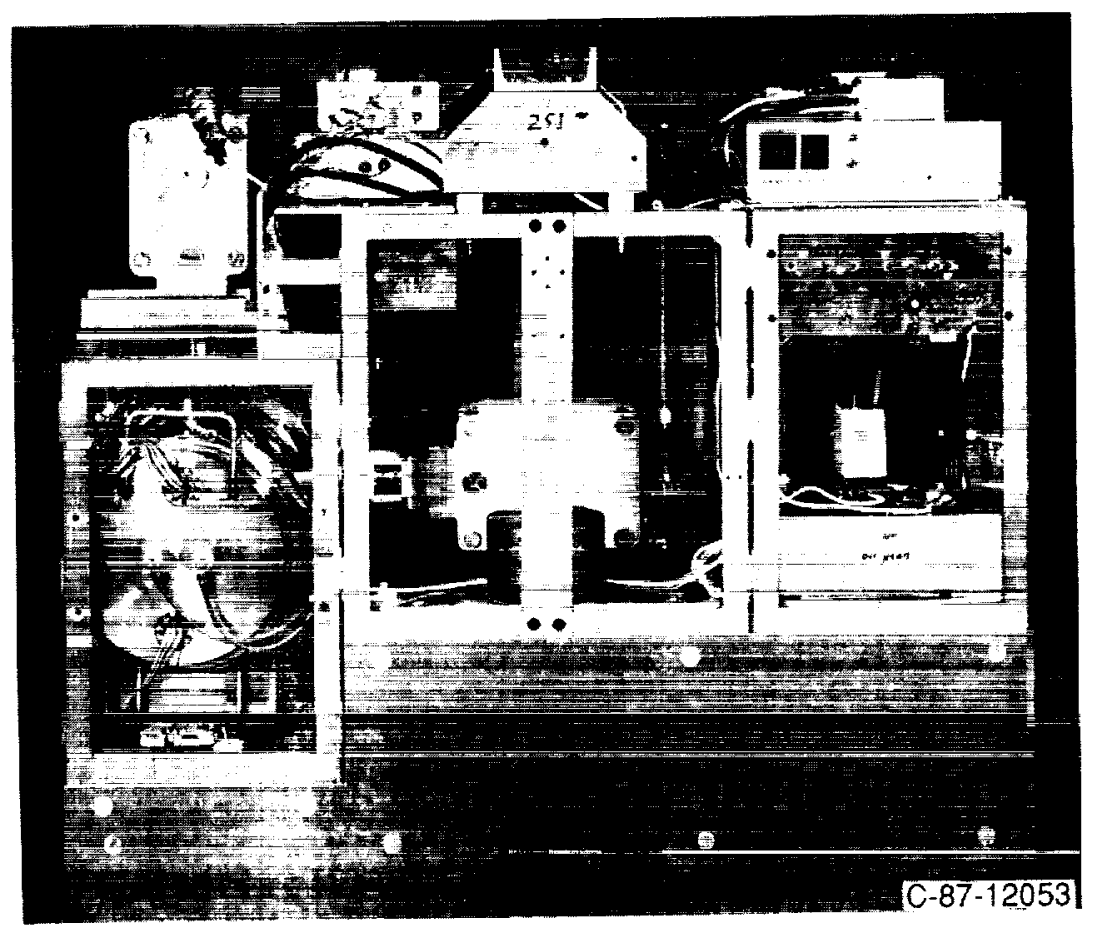

Figure 5. - Droplet combustion experiment drop tower apparatus.

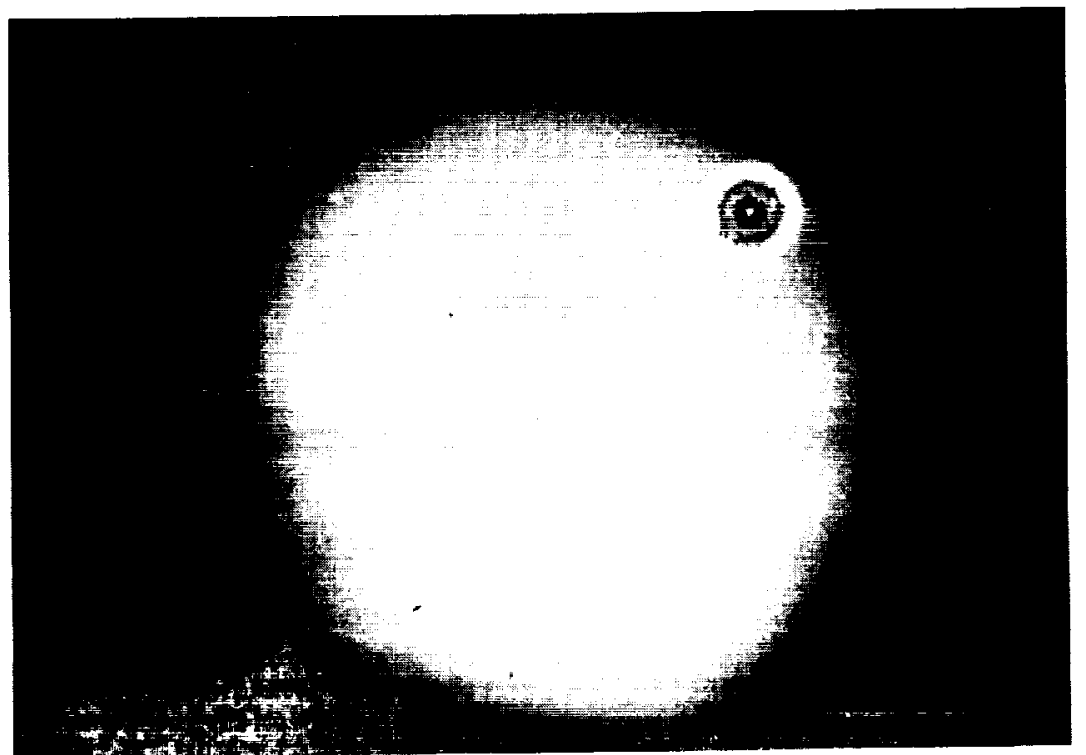

Figure 6. - Burning decane droplet in air. 


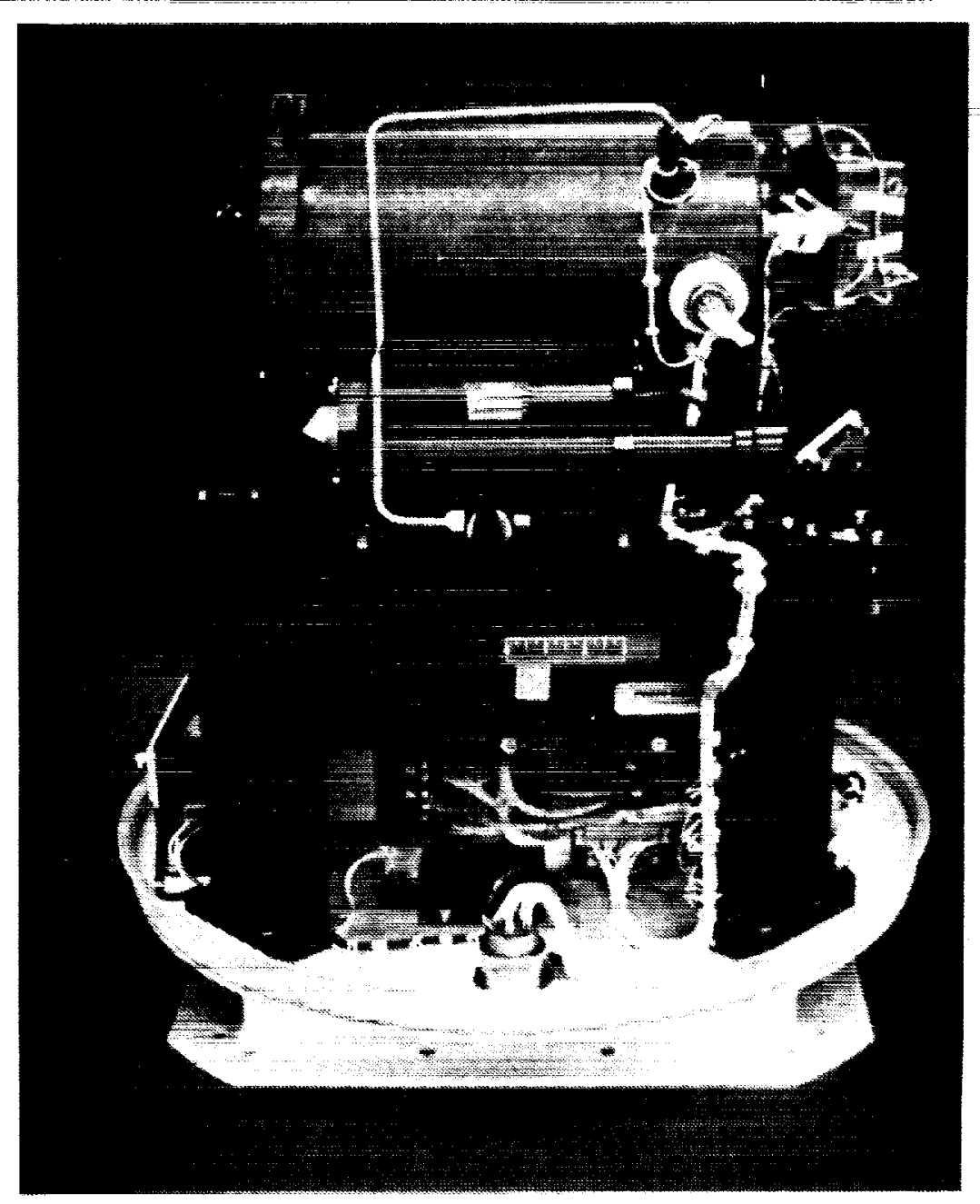

Figure 7. - Droplet combustion experiment engineering hardware.

ORIGINAL PAGE

BLACK AND WHITE PHOTOGRAPH 


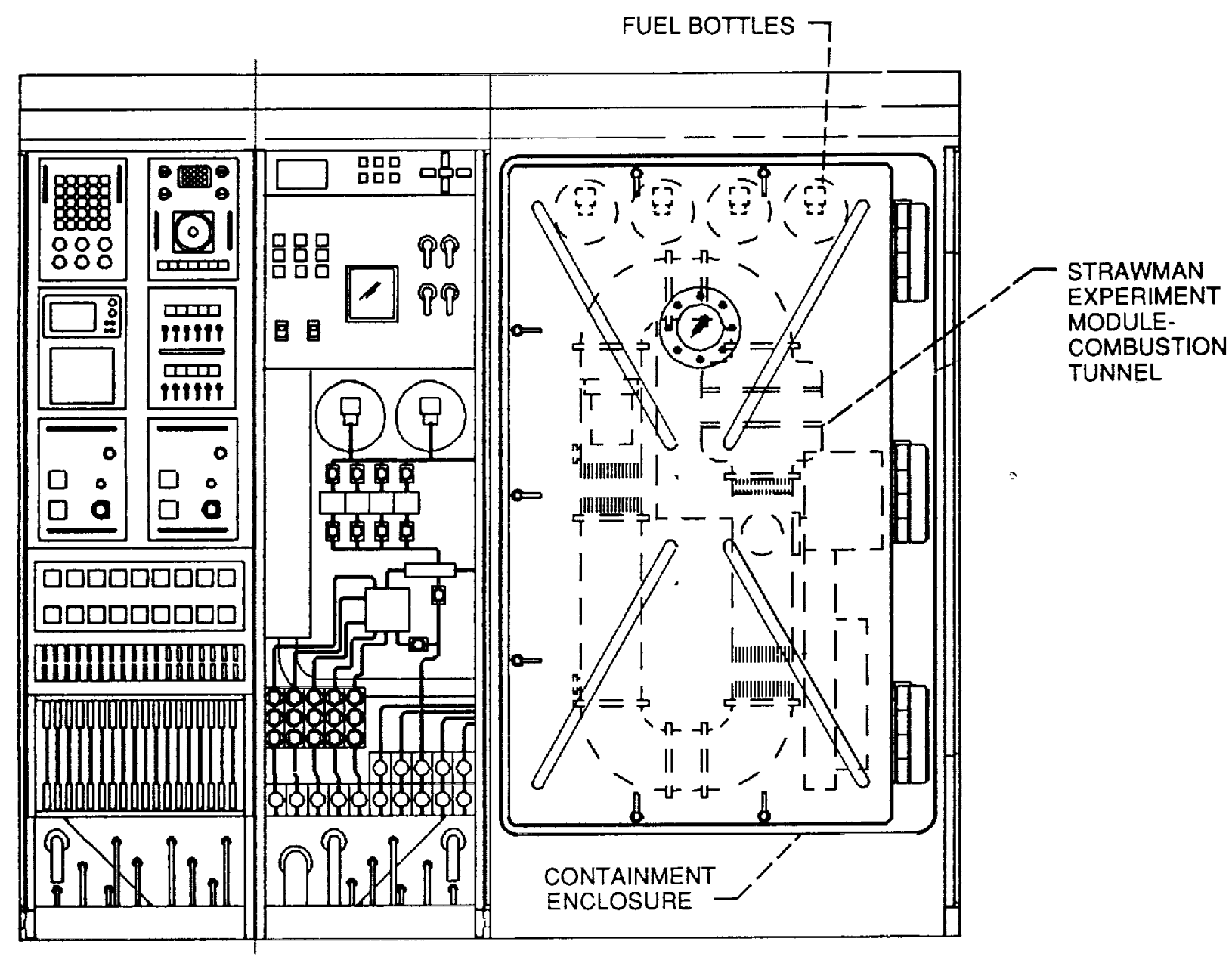

Figure 8. - Modular combustion facility schematic concept. 
(1) OPTICAL DETECTOR ELECTRONICS

(2) ADDITIONAL SIGNAL CONDITIONERS

(3) OPERATOR INTERFACE PANEL

(4) DATA ACQUISITION \& CONTROL MICROPROCESSOR (MDM) WIEXPANSION BOX

(5) POWER CONTROL UNIT

(6) VIDEO SYSTEM CONTROLLER

(7) POWER CONVERSION UNIT

(8) MASS SPECTROMETER

(9) Us LAB INTERFACE PANEL

(10) LASER

(11) MASS FLOW CONTROL MODULE

(12) EXPERIMENTAL PRODUCTS

(13) GAS MIXING SYSTEM

(14) VALVE BLOCK

(15) FUSE BLOCK

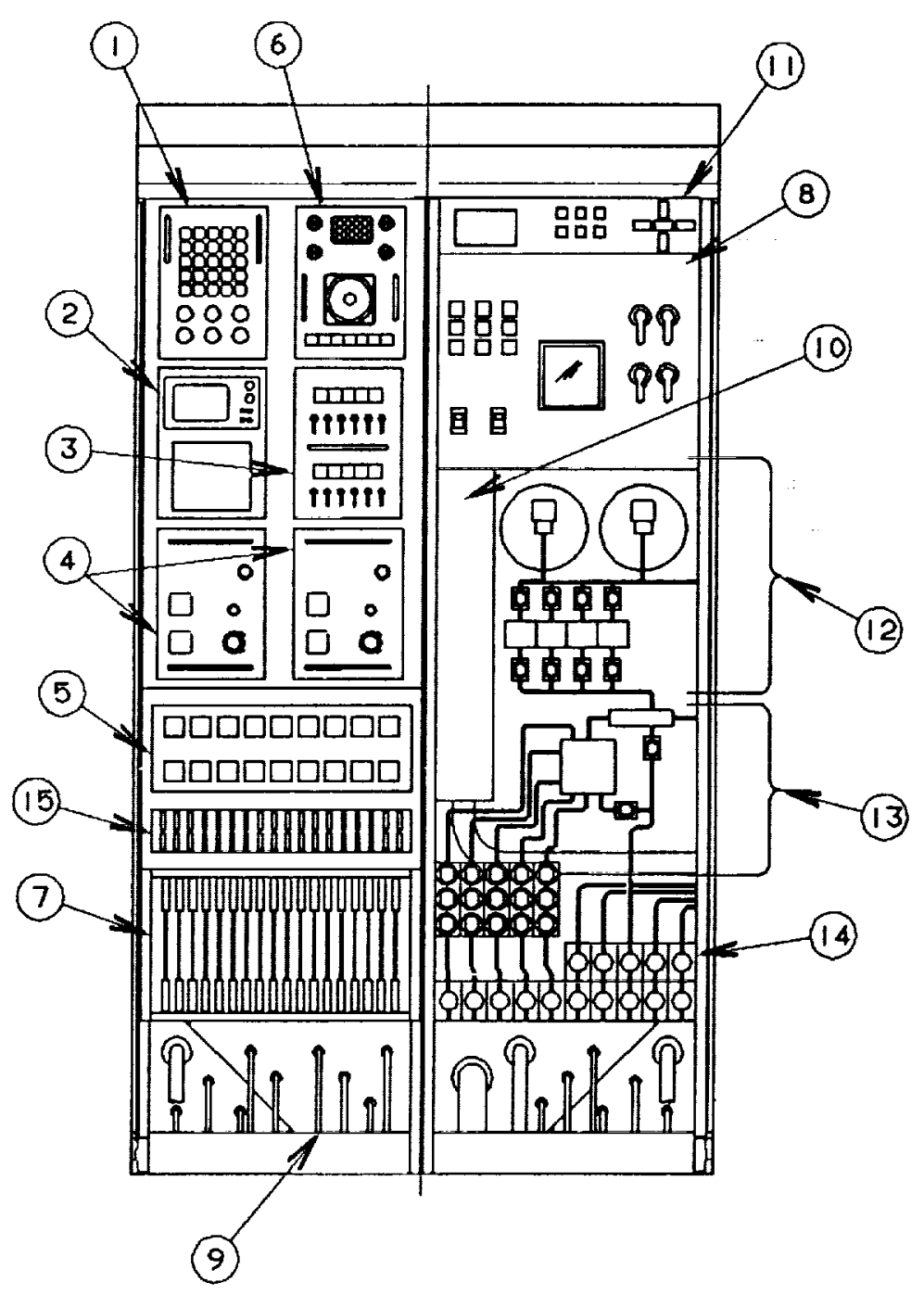

Figure 9. - Modular combustion facility resource rack contents concept. 


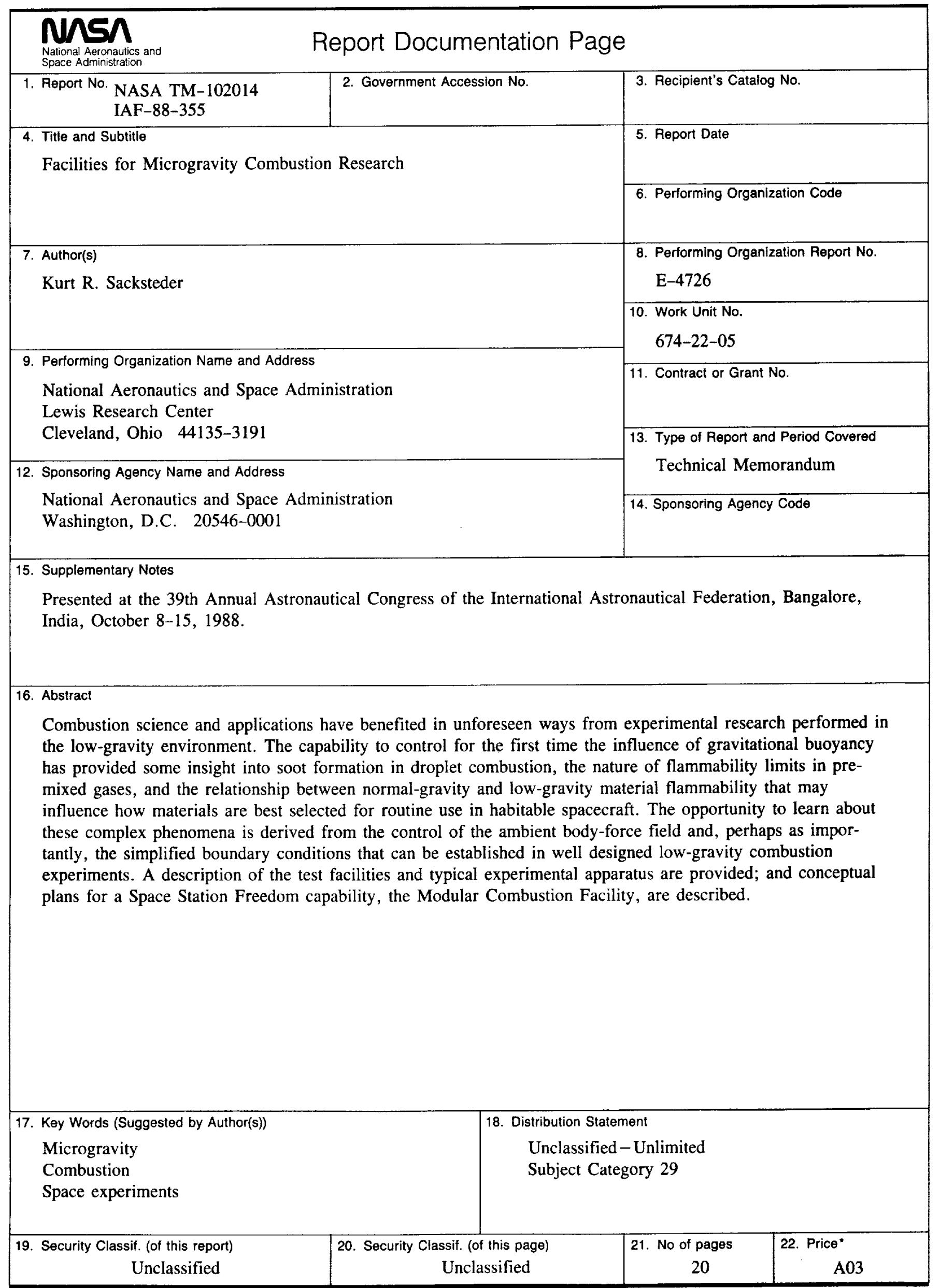


